Conference Paper

\title{
Development of a novel remanufacturing architecture for lithium-ion battery packs
}

Kampker, A., Heimes, H., Lienemann, C., Grauel, D., Jones, M

This is a paper presented at the Electric Vehicles International Conference (EV), Bucharest, Romania, 5-6 Oct 2017

Copyright of the author(s). Reproduced here with their permission and the permission of the conference organisers.

\section{Recommended citation:}

Kampker, A., Heimes, H., Lienemann, C., Grauel, D., Jones, M (2017) 'Development of a novel remanufacturing architecture for lithium-ion battery packs'. In: Proc 2017 Electric Vehicles International Conference (EV), Bucharest, Romania, 5-6 Oct 2017. doi: 10.1109/EV.2017.8242090 


\title{
Development of a novel remanufacturing architecture for lithium-ion battery packs
}

\author{
Achim Kampker ${ }^{1}$, Heiner Heimes ${ }^{1}$, Christoph Lienemann ${ }^{1}$, Daniel Grauel ${ }^{1}$, Martyn Jones ${ }^{2}$ \\ ${ }^{1}$ Chair of Production Engineering of E-Mobility Components of RWTH Aachen University, Aachen, Germany \\ ${ }^{2}$ Glyndŵr University, Wrexham, Great Britain
}

\begin{abstract}
With a rapid growth in the lithium-ion battery technology, particularly in the automotive sector, remanufacturing concepts to ensure maximum efficiency levels may be seen as an attractive option. Such a process does not currently exist and the opportunity to undercut cost-intensive batteries and support green credentials is one which the market is now ready for, namely, an alternative to buying new. A feasible remanufacturing concept can further reduce the current total cost of ownership with an adequate solution under consideration of the current amount of battery pack returners. With this in mind, this research provides a transparent remanufacturing architecture, which can handle a capacity of 5,000 up to 20,000 battery packs per year, depending on the selected degree of automation, manual, hybrid or fully automated. Furthermore, different tools from a factory planning structures will be applied on purpose of an industrial feasible concept. In addition, the assessment considers diverse scenarios of the battery module reusability to ensure a realistic forecast. Consequently, the potential for this outlined concept will compete for an increasing sector of a global market, which is expected to rise to 1.3 billion cars by 2030 and there is a growing interest in electric vehicles. Therefore, any innovations in battery production (and which will include the concept of remanufacturing) have the opportunity to challenge existing business models of practice while further reducing costs for the future customer of tomorrow.
\end{abstract}

\section{INTRODUCTION}

The optimization of electrical driving technology is a compelling necessity particularly given the future availability of fossil fuels and the need for rapid and sustained reductions in the carbon environmental impact (footprint). As an emerging technology with a significant potential for reducing carbon dioxide $(\mathrm{CO} 2)$ emissions, electric vehicles (EVs) appear to be the future of transportation in a world which requires the human race to treat the planet with greater respect. [1] Likewise, plugin hybrid electric vehicles (PHEVs) can also make a contribution toward the reduction of carbon emissions by up to $60 \%$ in comparison to conventional hybrid vehicles. [2] Such considerations have resulted in research which is determined to increase efficiency levels for the electrical vehicle. Since EVs are equipped mostly with lithium-ion batteries and the demand for EVs is growing fast. The future of the automotive industry will require billions of lithium-ion batteries (LIB). Consequently, there is a need for processes to recover the material and components (e.g. remanufacturing) for any used batteries that will offer a second life cycle for almost depleted batteries. [1] Currently, no such remanufacturing processes exists, which severely inhibits any claims that the industry maximizes its efficiency levels for the benefit of the eco-system. Such criticisms harm any green claims made by the industry, which has determined that the lithium-ion battery is the way forward. Therefore, this study seeks to research the possibilities and feasibilities of remanufacturing in an effort to identify the potential benefits to the industry and the ecology of the Earth. Currently, diverse research projects, such as BatteReMan [3] and ABACUS [4] attempt to investigate the potential for remanufacturing. Therefore, the motivation for this work is to contribute to the collective effort currently being made.

\section{STATE OF THE ART}

\section{A. Lithium-ion battery package}

A lithium-ion battery package is a complex system with several inter-related components discharging a range of different functions, for example, power generation in cells or the measurement of essential parameters, like voltage. Fig. 1 displays a principled view of a battery pack with (a) Battery module (b) Cooling system (c) BMS master (d) High voltage module (e) Contactor (f) Insulation package (g) Casing (h) Isolation module (i) Tension (j) Cylinder cell design (k) Central module contactor system (1) Sensors (m) BMS slave platina (n) Module housing. The design can vary within the industry based on the design need, manufacturing process, cell geometry or the limited space allocated within engine design. However, each lithium-ion battery pack can generally be divided into three power levels, that is, the cell, the module and the full package. The first stage of the power level focusses upon the cell which produces an internal chemical reaction resulting in the generation of electrical energy. The cell geometry can vary depending on the manufacturer's choice of design as outlined, that is, pouch-bag, cylindrical \& prismatic. As a single cell generates 3-4 V [5], which is considered harmless to human, health and safety issues should not over-burden the manufacturer during either production or post-production phases. At the second stage, the module consists of several cells and therefore, the potential for hazards increases. 


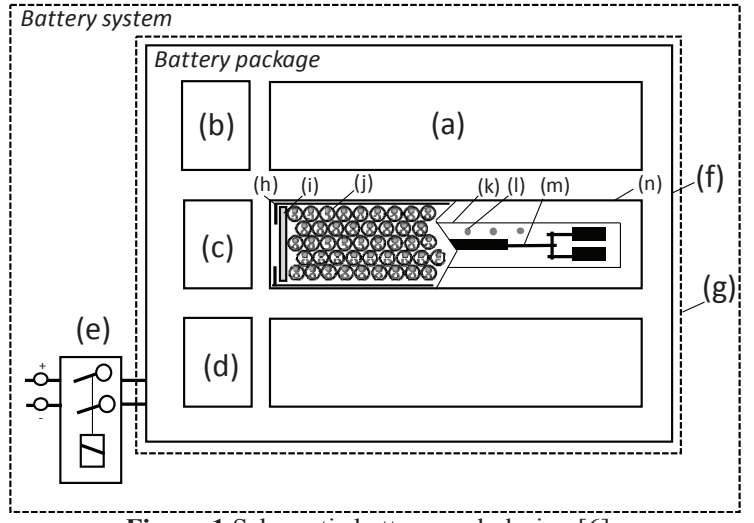

Figure 1 Schematic battery pack design [6]

Moreover, the module has several sensors to monitor each cell and a system is needed to balance the performance of each individual cell in relation to the system. Finally, the battery pack requires the highest power level and is, therefore, more difficult to monitor with an increasingly higher risk of hazard based on voltage level which generates around $360 \mathrm{~V}$ [5].

\section{B. Complexity of systems and assembly process}

The lithium-ion battery pack is a multifaceted system which consist of several different components. Although each of the components has the own complexity and therefore potential for improvement, for instance a wireless operation or a new temperature system, current research has huge possibilities for enhancement as the adoption of newer technologies add to further developments. Finally, the complex inter-relationship between individual parts and their design possibilities need to be considered carefully to ensure that their maximum potential is achieved [7]. The assembly process is a significant step prior to the lithium-ion battery pack but may be implemented during the application phase. Kampker et al. [8] and the RWTH Aachen University have published an appropriate conceptual framework for the assembly procedure which includes a simplified model of a cell used as an example of how the process will unfold. Subsequently, the following sections are mainly focussed on this study with additional information from other researchers considered.

The general structure of the assembly from that battery pack can be divided into the three phases: assembly of the module, assembly of the battery pack and a testing phase, post process, as indicated in Fig. 2. Lithium-ion batteries have a certain lifetime particularly when related to driving technology which determines its nominal capacity as it demands power. That means the nominal capacity is only economically applicable to customer vehicles when it retains $80 \%$ efficiency levels.

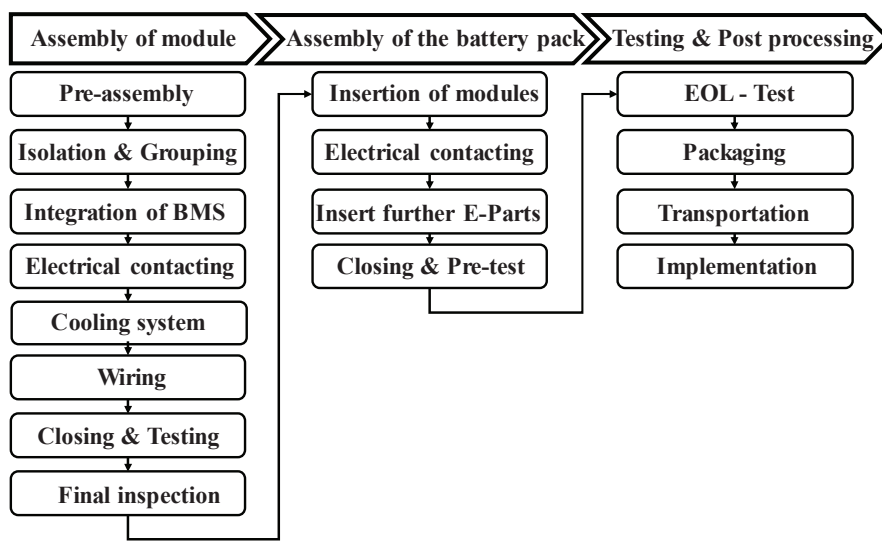

Figure 2 Assembly procedure of a battery pack [8], [9]
After this point, the battery pack may not achieve the necessary range of motion required, resulting in a loss of reliability and performance. Furthermore, Foster et al., [10] have assumed an average lifetime of a lithium-ion battery to be between 8 to 10 years. However, this argument cannot be confirmed universally at this point due to a lack of longer-term studies providing more methodical data. Therefore, the validation of the forecast models may be achieved in five years but this depends on the manufacturer's willingness to provide what may be commercially sensitive analysis. Nevertheless, the research community addresses the second life cycle of lithiumion battery according to its perceived future needs, for example, new technologies and methods for reuse or recycling will determine some further implications. In this context, contemporary research delivers three possibilities and Foster et al., [10] introduces these options in his study, namely remanufacturing, repurposing and recycling. In this present work, the focus lies in the remanufacturing of used electric vehicle batteries based on lithium-ion.

\section{ANALYSIS OF REMANUFACTURING PROCESS}

\section{A. Main steps of remanufacturing process}

Remanufacturing of products or components is a fastgrowing business, particularly in the automotive area, for instance, turbocharger, steering's or transmission components. One new possibility in the near future could be the remanufacturing of a battery pack. At this juncture, no industry and no research community can provide a feasible concept, which can handle the remanufacturing of LIB in an adequate number of pieces. In general, a concept can be divided into five essential phases, as shown in Fig. 3.

\section{B. Determination of process functions}

The Determination of process functions is essential for the entire future layout to establish a realistic design. Errors at the stage of functions will influence the outcome with a particular risk potential. The function schematic is idealized and drawn in a horizontal diagram, as illustrated in Fig. 4 (with A - Receiving department; B - BOL BP; C - Disassembly pack; D - Check \& Prep. Cable etc.; E - Check \& Prep. BMS; F - Check \& Prep. BC; G - Check \& Prep. BM; H - Refurbishment BC; I Classification BM; J - Storage; K - Assembly; L - EOL; M Packaging/ Finished goods store; N - Shipping of the developed remanufacturing concept). Station A. to $\mathrm{C}$. have linear connection where the main incoming units of the $\mathrm{BP}$ are controlled, tested and dissembled. Afterwards the flow is separated into individual workstation D, E, F and G. Station G (Check of the BM) requires a further station I (Classification of the $\mathrm{BM}$ ) for handling a higher factor of $\mathrm{BM}$ compared to the other units. On the other hand, station $\mathrm{H}$ is necessary for the preparation of the outer appearance from the external housing components with the help of painting operations. The reason is that customers want products that look like new. Finally, all parts will be collected in a storage system in order to decouple the production flow. The last sections from station $\mathrm{J}$ until $\mathrm{N}$ are also directly linked, resulting in a potential for bottlenecks. The first section (Station A-C) includes a push flow in respect to a separation of the parts as soon as possible regarding the hazard risks of battery cells.

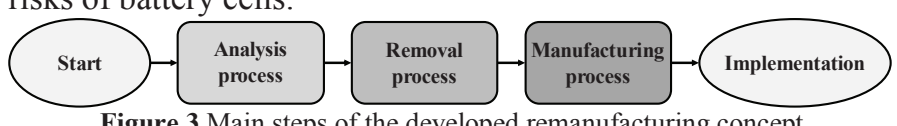

Figure 3 Main steps of the developed remanufacturing concept 


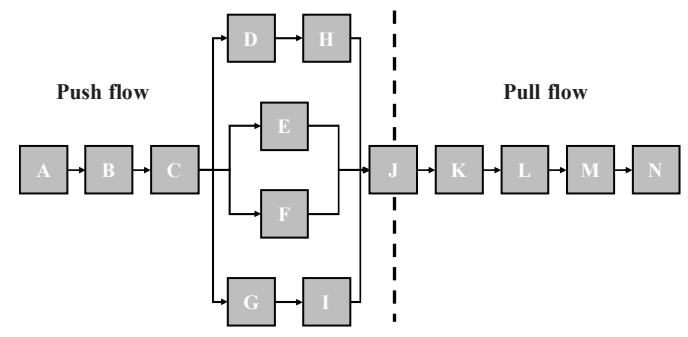

Figure 4 Flow types for battery remanufacturing

After the storage system, the process changes into a pull flow, depending on customer demands. The idealized structure will build the foundation for the subsequent steps, such as the determination of equipment, human resources and areas. Based on this stage in the feasibility study, the dimensioning of each section still has a certain potential for variation. Layout and design for the required equipment, human resources and areas is based on available literature about battery recycling and assembly processes in combination with specific prediction techniques in the factory planning area.

\section{Determination of equipment}

The number of equipment depends on the total capacity demand and the available capacity of the machines. Furthermore, the degree of automation plays a role in the prediction and the current level of technology. This research considers the following degrees of automation:

- manual,

- $\quad$ hybrid (semi-automated),

- fully automated.

Taking this into account, the determination of the equipment is a complex process, and the demand for remanufactured BP is unknown at this time. Therefore, the identified information from BMW i3 [11], VW UP [12], LIBRI [13], [14] and information from the reference pack will help to determine the amount of equipment. A cycle time assumption for three possible automation degrees will allow a determination of the required equipment. Fig. 5 combines the developed function schematic with an estimation of time consumption for a manual concept on basis of the available literature and assembly times from the reference pack. However, this option is very inefficient in terms of unbalanced push and pull flows. The bottlenecks in the process are stations $\mathrm{C}$ (Disassembly) and $\mathrm{K}$ (Assembly). Consequently, a splitting of these stations in sub-stations is required in order to have an appropriate and smooth production flow.

Manual Concept: Based on these results, the upgraded cycle time assumption displays an optimized flow characteristic, as depicted in Fig. 5. But, new bottlenecks arise at station BOL (B) and EOL (L). A battery test system requires around 20 to 30 min [15], [16]. However, a breakdown of these stations in further positions is not possible. Only a parallel operation can supply the demand from the station of disassembly (C) with the new subdivided stations. In addition, the handling icons demonstrate significant steps for each position. In summary, a remanufacturing concept on the basis of a manual approach can expect nearly 24 stations with 19 manual workplaces, 1 Storage system and 4 test centres.

Hybrid Concept: A hybrid concept can increase the productivity and reduce the high variable cost of workers. Three human-robot-collaborative (HRC) systems e.g. from the company Fanuc (system CR-35iA) will be applied to the developed concept. The systems can handle a product weight of $35 \mathrm{~kg}$ each [17]. A robot system can work more efficiently and permanently compared to a human, which allows removing stations $\mathrm{C} 2, \mathrm{C} 3, \mathrm{~K} 3$ and $\mathrm{K} 4$. The elimination is possible in respect to a screwing and moving operations. However, a flexible cabling still needs a manual operation because of the non-defined position. Moreover, the original equipment manufacturer (OEM), like BMW and VW still have manual workplaces in the highly automated production systems for EV for the purpose of cabling. [11], [12]. In addition, the station $\mathrm{G}$ has also a HRC-system due to a better handling of the BM. The cycle time for the hybrid concept is assumed similar to the manual approach, and only trial can show the real values. This research will not include a validation with the help of a methods-time-measurement (MTM) technique, which can verify the final conditions. In conclusion, the provided hybrid concept requires eleven manual workplaces, four test centres, one storage system and three hybrid workplaces plus one combined station.

Fully automated concept: The fully automated remanufacturing concept involves less manual workplaces and a profoundly engineered system, including robot applications with a PLC and a combination of manual with automated handling, particularly at the stations of cabling. Moreover, it will be assumed that the automated concept should reach a cycle time of $\sim 5 \mathrm{~min}$ ( $1 / 3$ of the manual). That means the station BOL and EOL need to be doubled for the minimum production rate. Correspondingly, the cabling stations will be duplicated, resulting in a parallel operation. Besides, the check of the external housing components and small parts will require longer than 5 minutes. With this in mind, stations $\mathrm{D}, \mathrm{E}$ and $\mathrm{H}$ will be outsourced, and the material will be checked externally. All in all, the automated concept leads to an individual and compressed product flow in order to achieve a high-value stream. Hence, the complex assumptions of the automated concept the further process have the highest deviation potential due to the high number of variables. Nevertheless, the system requires eight test centres, one storage system with bigger structures compared to other concept ideas, one manual workplace for shipping, eight combined stations and seven robot stations.

\section{Determination of human resources}

The Human resources play a dominant role within the final product cost structures. Taking this into account, the determination of the number of employees is essential. In this context, the factory planning tools are oriented to define the demand, depending on the department, for instance, in the area of production, maintenance and quality. This research is focused on the production site according to the feasibility study. Generally, the number of operators can be defined via a qualitative or quantitative technique, such as the estimation procedure, index method or work scheme method. [19]

The method Hiersig from et. al [20] will be used to determine the number of operators for the remanufacturing process. In terms of parameters, the production will run in one shift $(\mathrm{Zs})$ and the average working time is 230 days (ZDA) per year for a five working day week excluding two weeks maintenance service [21]. Based on the equipment determination, the manual remanufacturing process has 24 stations with 19 manual workplaces (AZ), and the hybrid solution has 20 stations with 12 manual operator demands. The fully automated solution has 25 stations with 9 manual tasks, where an operator is required. Finally, the regular working time per day (TS) is 7.5 hours excluding a 30 minutes break. Furthermore, different factors 


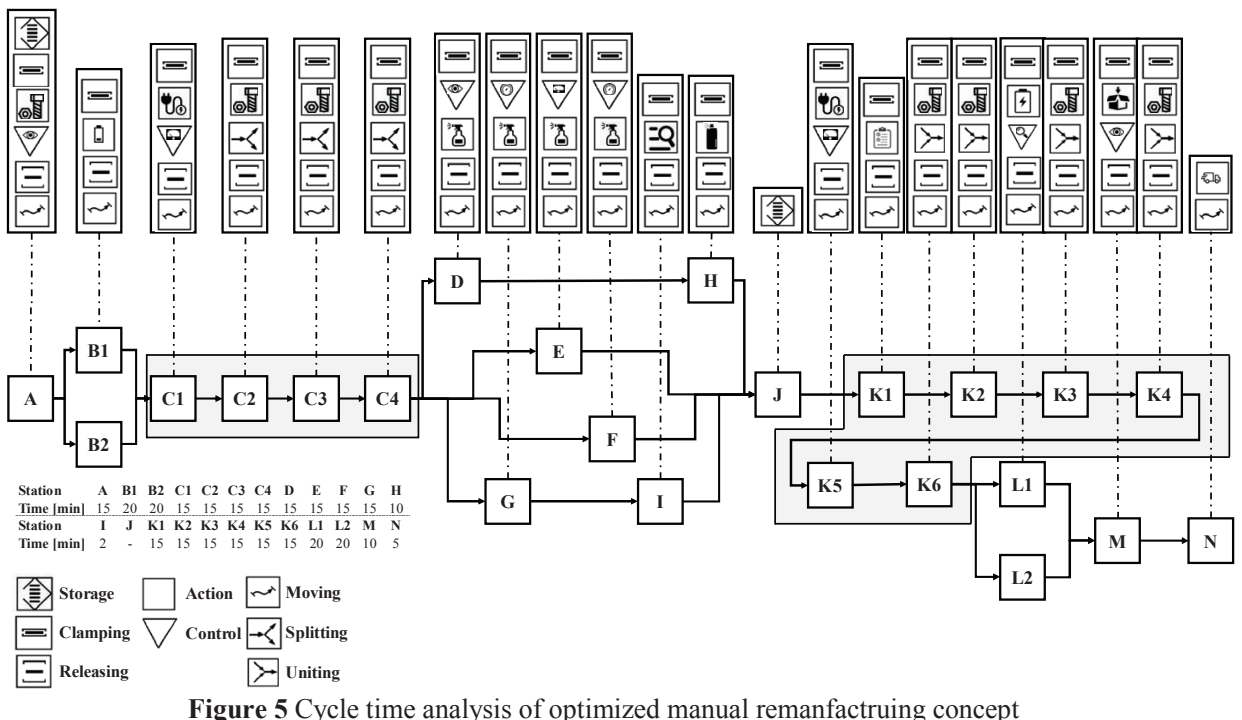

will be applied, such as the error time factor $(\mathrm{FF})$. This factor contains the potential that the operator is not present. The factors were defined by means of literature [22-24]. The machine capacity (TM), the human capacity (TP) and the need of operators $(\mathrm{P})$ are calculated using the following formulas:

$$
\begin{aligned}
& T_{M}=Z_{\mathrm{E}} \approx Z_{\mathrm{fh}} \times A Z \text { * } T_{\mathrm{s}} \\
& \mathrm{T}_{\mathrm{E}}=\mathrm{T}_{\mathrm{M}}: \frac{(\mathrm{AZ}-\mathrm{AZM}+\mathrm{AZA})}{\mathrm{AZ}} \\
& \mathrm{P}=\frac{\mathrm{T}_{\mathrm{P}} \times\left(1+\mathrm{F}_{\mathrm{A}}\right) *\left(1+\mathrm{F}_{\mathrm{W}}\right)}{\mathrm{Z}_{\mathrm{G}} * \mathrm{~T}_{\mathrm{E}}}:\left(1+\mathrm{F}_{\mathrm{F}}\right)
\end{aligned}
$$

The outcome expresses that a manual concept requires a minimum of 23 workers, the hybrid solution 15 and the fully automated 11. Besides, a supervisor is required to coordinate the service, a holiday replacement for the operators and additional support during peak phases of production.

\section{E. Determination of areas}

Under consideration of the proposed study from Treffer et. al. [25], the average dimension of an EV- battery pack is assumed to be $1 \mathrm{~m} \mathrm{x} 2 \mathrm{~m} \times 0.5 \mathrm{~m}$ with a weight of $250 \mathrm{~kg}$. The used reference pack in this research has a dimension of $1.4 \mathrm{~m} \mathrm{x} 0.5 \mathrm{~m}$ x $0.3 \mathrm{~m}$ with $300 \mathrm{~kg}$. Therefore, the area of BP can be estimated with a safety factor of 1.2 , which results into $2.5 \mathrm{~m}^{2}$. The previous determination of the equipment for each station delivers the input for the area prediction, and this data will be entered in the equations depending on their operation side. The calculation for the area includes not only the machine but also, other sub-areas, such as the working area, transportation area and supply area. These areas are significant to provide a suitable working environment and to reduce the potential of incorrect area estimations. Besides, Roemisch et. al [26] presented a classification table, which includes typical areas for a workstation in a factory. For instance, an assembly area for one worker is assumed by Schenk et. al [27] in a range of 25 to 50 $\mathrm{m}^{2}$ and the calculated value in this research is $26.23 \mathrm{~m}^{2}$. Consequently, the outcome of the calculated values can be validated with this data. In general, a manual concept will take more area compared to an automated area, which shows the ratio of the different production types in. The disassembly station (C) and assembly station (K) take the most space in accordance with the number of operations. Furthermore, the
BOL (B) and EOL (L) have a high space consumption in order to prevent safety risks and to provide sufficient space for the housing as well as for the option of an automated process.

\section{F. Determination of material flow}

Generally, the material flows in an industrial case can be distinguished into internal and external flows. Modern factories, as well as logistic planning, try to achieve a holistic approach under consideration of the entire supply chain, such as supplier, manufacturer and customer. [28], [29]

In the current situation of a BP remanufacturing has only a few $\mathrm{PB}$ returners, notwithstanding growth of number of $\mathrm{BP}$ returners in the near future. In this context, an annual BP amount of 2000 returner will be assumed to detect the material flow, which goes through the 14 main stages. Finally, all developed data can be implemented in a Sankey diagram. The model is calculated with an assumption of 2,000 BP per year and that approximately $5 \%$ can be directly recycled after the BOL in terms of errors, such as damage or leakage. The waste percentage is so trivial in regard to the selection requirements because no BP will be remanufactured after an accident or other mechanical influences. After this BOL, the BP will be disassembled into the four-main units, BM, BMS/HV-Box, Cable \& small parts and the external housing of base and cover. Previously mentioned, the highest value stream is the BM with a factor 10, resulting 19,000 $\mathrm{BM}$ by the assumed annual production. Therefore, the check station of the BM has a greater amount of effort in order to classify the current performance level. The other check stations for the BMS, cables and small parts will verify the state of the parts with around 1,900 units. Subsequently, a BM is suitable for a remanufacturing concept for EV until a SOH level of $80 \%$ due to the economic aspect. A level under $80 \%$ to $30 \%$ still provides the possibility of second life, such as an electricity storage system for renewable energy resources, like wind or solar. [30] However, this path will not be considered in depth in this study. In the case of a capacity higher than $80 \%$, the BM can be reused and newly arranged to obtain a BP with a similar capacity level. The technology in the area of LIB for EV has still a lack of experience, particular with the long-term field test at the stage of the BM or BP. The behaviour of BM and BP over 10 years is not classified due to the recently new application. Hence, this research assumes three scenarios for reusing of BM; worst-case scenario of $1 / 10 \mathrm{BM}$, the middle scenario of $3 / 10 \mathrm{BM}$ and the best-case scenario of $6 / 10 \mathrm{BM}$. It is assumed $2 \%$ of the BM during the classification- 
process cannot be used for a further purpose. In parallel, the BMS/HV-Box has a waste potential of apparently $10 \%$ according to experts from REMATEC. [31] Likewise, the cables can have a higher potential of damage, resulting from the assembly or disassembly process. Therefore, a doubled waste potential for cables is suggested. Finally, the housing parts are very robust, which is confirmed by the reliability analysis. Hence, for the external housing parts a waste rate of $5 \%$ is assumed and the other $95 \%$ of the components require a refurbishment for an acceptable appearance. All parts will be collected in the storage system, which allows a decoupling from the push and pull flow. Subsequently, the assembly process will be fed by the storage and the system can handle around 1710 BP per year. The assembly process has a potential of defects (1 $\%)$. In the next step, the EOL test analysis will check the BP with a full power test and nearly $5 \%$ will not directly pass to the packaging station. Failed BP's require a reassembly and another test approach again before the BP is ready for the packaging $(\mathrm{M})$ and shipping station $(\mathrm{N})$. Circa 1,692 BP can be remanufactured, depending on the contribution of new parts. That means that $15.4 \%$ of the input needs to be recycled per year.

In addition, the remanufacturing process has still the option of a further circle for the BM and a remanufacturing concept of the BM can be adapted. Based on the undeveloped disconnection process of the battery cells, the material flow chart is defined with percentages due the first impression. The procedure is similar to the BP concept, only the amount of parts and the rate of recycling are not equal. However, the concept underlies the design of the cells. For instance, a prismatic cell design has a smaller value stream with approximately 5 to 7 cells per BM compared to the cylindrical design option with approximately 200 cells (reference pack) for a similar energy density. A further aspect is that a prismatic cell has a better handling. Likewise, like OEM use a prismatic battery cell design in a fully automated process. [18]. On the other side, the components at the stage of the BM will be smaller and harder to grip, which influence particularly the analysis and verification process as well as the costs. With this in mind, cables and smaller parts with trivial acquisition costs can be directly recycled. A further approach for the remanufacturing process of the BM will not take place in this research until a suitable option of solving of the BM is developed. Therefore, the further process of the layout development is mainly focused on the remanufacturing of the $\mathrm{BP}$ without the further remanufacturing cycle of the BM.

\section{LAYOUT DEVELOPMENT}

The previous steps form the basis for the design of the layout. The elementary phase is a development of an ideal layout under consideration of the established remanufacturing characteristics. In order to determine a suitable layout, analytical, heuristically and visual methods can be applied and this research uses mainly the try-out method under consideration of experts group. Grundig et. al [19] and Pawellek et al. [133] confirm that the most used technique in the practice is the try-out method, leading to a realistic outcome.

\section{A. Layout classification}

The remanufacturing layout synchronizes the previous material flow results with a realistic design. In this connection, the material flow still has a potential of uncertainty and a potential of flexibility is required. That means the aim of the layout is to minimise the product flow time and work in progress and maximise machine utilisation. Therefore, Lim et al. [33] have proposed four possible layout types for a remanufacturing concept, cellular, fractal, holonic and job shop. Each type has own characteristics, for instance a cellular layout is suitable for concepts with a low mean flow time, a good work in progress (WIP) and moderate production volume. Also, the automotive industry uses the principle of just-in-time to keep a low storage. However, the remanufacturing cannot directly apply this principle. The reason is that a remanufacturing system uses the internal goods after the disassembly again and it has no completely new material stream for the BP. A cellular layout design is the most appropriate solution for the remanufacturing of $\mathrm{BP}$, having the low mean flow time between 5 to $20 \mathrm{~min}$ and high complexity. The selected cellular layout design will be connected with four possible material flow schematics, which are typically applied to a factory due to an ideal material flow.

\section{B. Layouts in detail}

The material shapes are idealized and the remanufacturing concept needs to consider the function schematic, the transport intensity and further factors. Consequently, each layout will be individually created. First of all, the development phase of layout considers that the storage system is flexible in this arrangement in contrast to other fixed station. The main reason is that the storage system is easily adaptable to certain areas unlike other stations, like the BOL or EOL with their space and safety restrictions. Each layout has individual features and arrangements for the stations (see Fig. 6). In terms of the layouts, the linear option (a) consumes more area in the horizontal dimension and has a two-side supply department. The U-shape (b) has both supply departments plus the main storage system on one side, resulting in a better material distribution and less transportation cost. Consequently, a benefits value analysis in the section of evaluation will determine the features of each layout idea.

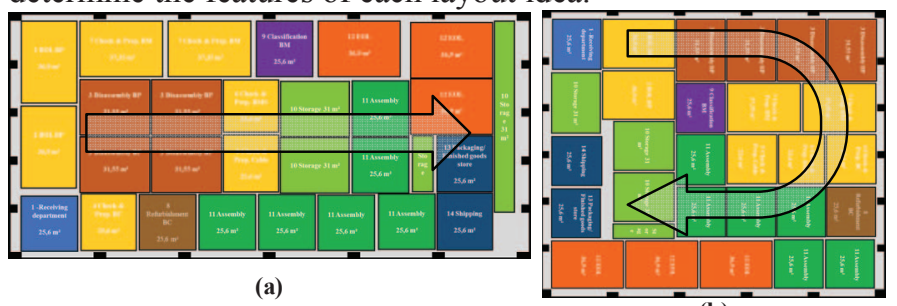

(b)

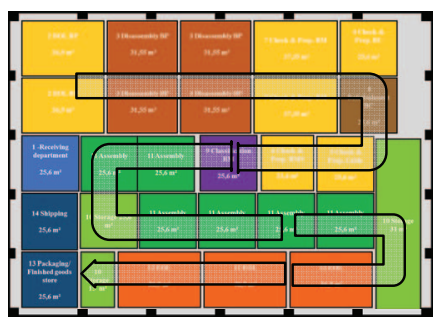

(c)

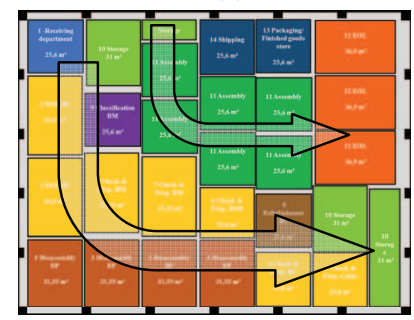

(d)
Figure 6 Layouts: (a) linear shape, (b) U-Shape, (c) S-shape \& (d) L-shape

\section{CONCLUSION AND OUTLOOK}

This study is oriented on factory planning structures, starting from a flow chart and function schematic, over the equipment determination of three different automation levels: manual, hybrid and fully automated. In general, a remanufacturing concept in an industrial case requires an area of around 1,100 $\mathrm{m}^{2}$ with 11 to 23 workers. The material flow chart has shown that circa $15 \%$ of the incoming BP cannot be remanufactured 
due to errors before or during the process. All the developed data laid the groundwork for the layout with a cellular L-shape with the purpose of an ideal dual material flow and the flexibility of two value streams.

The proposed research has clarified the first foundation of a remanufacturing concept, by developing a theoretical approach, which was examined with factory planning techniques. The concept demonstrated that at the first stage a manual or hybrid concept is suitable with a handling of a low to medium demand in relation to an adequate investment volume. Consequently, the next possible step could be a realization of a small remanufacturing line with the new knowledge and a verification of the assumptions, resulting in specific expertise and a better understanding of the remanufacturing variables. Correspondingly, a closer look is required at each station, for instance which operation is necessary and which parameter is essential for the traceability, resulting in a better transparency of a remanufacturing concept. A modular structure for an example production line can investigate different kinds of arrangements and material flow effectiveness. A further factor is the safety aspect, the remanufacturing concept still has a risk potential based on the possibility of a thermal runaway and clarification of the battery parameters can build the foundation for a security concept, which may prevent the human and the environment from the hazards. On the other hand, a specific analysis of the properties of each component can also be beneficial, such as life time of the LIB, reliability and behaviour during the application. Also, the different scenarios must be evaluated regarding their properties, cost characteristics and concluding in break-even point analysis.

\section{ACKNOWLEDGMENT}

The results presented in this paper were achieved by the Chair of Production Engineering for E-Mobility Components (PEM) of RWTH Aachen University and funded by the federal state of North Rhine-Westphalia and the European Regional Development Fund (Europäischer Fonds für regionale Entwicklung - EFRE) of the European Union within the research project BatteReMan (EFRE-0800089).

\section{REFERENCES}

[1] Casals, L.C., Martinez-Laserna, E., García, B.E. and Nieto, N. (2016) 'Sustainability analysis of the electric vehicle use in Europe for $\mathrm{CO} 2$ emissions reduction', 127(1), pp. 425-426.

[2] Christopher, Hoehne, G., S. and Mikhail, V. Chester (2016) 'Optimising plug-in electric vehicle and vehicle-to-grid charge scheduling to minimize carbon emissions', 115(1), pp. 646-647.

[3] RWTH Aachen University (23.08.2016) BatteReMan, Available at: http://www.pem.rwth-

aachen.de/cms/PEM/Forschung/Projekte/ kvia/BatteReMan/ (Accessed: 24th June 2017).

[4] The University of Warwick (02.02.2016) Shaping the future with WMG, Available http://www2.warwick.ac.uk/fac/sci/wmg/research/energy_electrical_syste $\mathrm{ms} /$ projects/abacus/ (Accessed: 24th June 2017).

[5] Saw, L. H., Ye, Y. and Tay, A. A.O. (2016) 'Integration issues of lithiumion battery into electric vehicles battery pack', Journal of Cleander Production, 113(), pp. 1032-1045

[6] Wegener, K., Chen, W.H., Dietrich, F., Dröder, K. and Kara, S. (2015) 'Robot-Assisted Disassembly for the Recycling of Electric Vehicle Batteries', Procedia CIRP, 29(), pp. 716 - 721.

[7] Tornow, A., Andrew, S., Dietrich, F. and Dröder, K. (2014) 'Impact of multi-material components on the assembly and disassembly of traction batteries', Procedia CIRP,29(), pp. 792 - 797.

[8] Kampker, A., Deutskens, C., Heimes, H. H., Nowacki, C., Maiser, E. and Michaelis, S. (2012) Der Montageprozess eines Batteriepacks, Germany: WZL und VDMA Eigendruck
[9] Kleine-Möllhoff, Benad, P., H., Beilard, F., Esmail, M. and Knöll, M. (2012) Die Batterie als Schlüsseltechnologie für die Elektromobilität der Zukunft Herausforderungen - Potenziale - Ausblick, Reutlingen: ESB Business School Reutlingen

[10] Foster, M., Isely, P., Standridge, C. R. and Hasan, M. (2014) 'Feasibility assessment of remanufacturing, repurposing, and recycling of end of vehicle application lithium-ion batteries', Journal of Industrial Engineering and Management, 7(3), pp. 698-715.

[11] Bimmerfest (2013) BMW i3 Battery Production, Available at: 9th August 2017(Accessed: https://youtu.be/iiJsKza5CF4).

[12] TestDriven (2014) VW e-up Battery Production, Available at: 9th August 2017(Accessed: https://youtu.be/5VSiHxETfDc).

[13] Treffer, F. (2011) Entwicklung eines realisierbaren Recyclingkonzeptes für die Hochleistungsbatterien zukünftiger Elektrofahrzeuge, Hanau: Lithium-Ionen Batterierecycling Initiative.

[14] Kwade, A. and Bärwaldt, G. (2012) Recycling von Lithium-IonenBatterien, Braunschweig: LithoRec.

[15] Neubauer, J. S., Pesaran, A., Williams, B., Ferry, M. and Eyer, J. (2012) 'A Techno-Economic Analysis of PEV Battery Second Use: RepurposedBattery Selling Price and Commercial and Industrial End-User Value', SAE 2012 World Congress \& Exhibition, (), pp. 1-13.

[16] Casals, L. C., Garica, B. A. and Benitez, M. M- G. (2014) 'A cost analysis of electric vehicle batteries second life businesses', Conference Paper, (), pp. 1-12.

[17] ROBITIQ (2016) Collaborative Robots Buyer's Guide, Lévis: ROBITIQ.

[18] Bimmerfest (2013) BMW i3 Battery Production, Available at: 9th August 2017(Accessed: https://youtu.be/iiJsKza5CF4).

[19] Grundig, C.-G. (2015) Fabrikplanung: Planungssystematik - Methoden Anwendungen, 5th edn, München, Hanser.

[20] Hiersig, H. M. (1995) Lexikon Produktionstechnik Verfahrenstechnik [Online], Berlin, Heidelberg, Springer. Available at http://dx.doi.org/ 10.1007/978-3-642-57851-9.

[21] Statistisches Bundesamt (2017)

[22] Eversheim, W., Robens, M. and Witte, K. W. (1977) 'Planung des Personals', in Z. Taylor (ed.) Entwicklung einer Systematik zur Verlagerungsplanung. Eversheim, Robens, W., M. and Witte, K. W.: Westdeutscher Verlag, pp. 157-181.

[23] Schuh, G. (2007) Produktionsplanung und -steuerung: Grundlagen, Gestaltung Und Konzepte [Online], Dordrecht, Springer. Available at http://gbv.eblib.com/patron/FullRecord.aspx?p=416991

[24] Armstrong, M. (2006) A Handbook of Human Resource Management Practice [Online], Kogan Page. Available at https://books.google.de/books?id=D78K7QIdR3UC

[25] Treffer, F. (2011) Entwicklung eines realisierbaren Recyclingkonzeptes für die Hochleistungsbatterien zukünftiger Elektrofahrzeuge, Hanau: Lithium-Ionen Batterierecycling Initiative.

[26] Roemisch, P. and Weiß, M. (2014) Projektierungspraxis Verarbeitungsanlagen: Planungsprozess mit Berechnung und Simulation der Systemzuverlässigkeit [Online], Wiesbaden, Springer Fachmedien Wiesbaden. Available at http://dx.doi.org/10.1007/978-3-65802359-1.

[27] Schenk, M., Müller, E. and Wirth, S. (2010) Factory Planning Manual: Situation-Driven Production Facility Planning [Online], Berlin, Heidelberg, Springer-Verlag Berlin Heidelberg. Available at http:// site.ebrary.com/lib/alltitles/docDetail.action?docID $=10351700$

[28] Grundig, C.-G. (2015) Fabrikplanung: Planungssystematik - Methoden Anwendungen, 5th edn, München, Hanser.

[29] Schenk, M., Wirth, S. and Müller, E. (2014) Fabrikplanung und Fabrikbetrieb: Methoden für die wandlungsfähige, vernetzte und ressourceneffiziente Fabrik [Online], 2nd edn, Berlin, Springer Vieweg.

[30] Menne, S. (2017) End-Of-Life Solutions für eCar-Batterien Entwicklung hybrider Leistungsbündel und Informationssysteme zur Entscheidungsunterstützung (EOL-IS), Available at: http://www.eolis.de/projekt (Accessed: 10th August 2017).

[31] Dietrich, F. and Hugel, P. (personal communication at REMATEC Amsterdam, July 18, 2017)

[32] Pawellek, G., (2014): Ganzheitliche Fabrikplanung. Grundlagen, Vorgehensweise, EDV-Unterstützung. 2. Aufl. Berlin: Springer Vieweg (VDI-Buch). Available: http://dx.doi.org/10.1007/978-3-66243728-5.

[33] Lim, H. and Noble, J. S. (2006) 'The impact of facility layout on overall remanufacturing system performance', Int. J. Industrial and Systems Engineering, 1(3), pp. 2006. 